\title{
Foundations of sustainable food waste solutions: innovation, evaluation, and standardization
}

\author{
Callie W. Babbitt ${ }^{1}$
}

Published online: 15 May 2017

(C) Springer-Verlag Berlin Heidelberg 2017

Faced with a growing population and a shrinking pool of natural resources, society faces an unprecedented challenge to provide a sustainable food supply, made even more complex by the lost and wasted food that accumulates at each step from "farm to fork."

Food loss and food waste presents a dual affront to resource use and ecological health. The 1.3 billion tons of food waste generated each year (Gustavsson et al. 2011) corresponds to immense inputs of energy, water, and nutrients. In the USA, as much as $20 \%$ of the national energy budget is associated with food systems, mostly due to inefficiencies in industrial food production (Pimentel et al. 2008; Canning et al. 2010). Globally, food supply chains put significant strain on freshwater resources and return excess loads of nitrogen and phosphorus that threaten the health of vulnerable ecosystems. Further, managing this food waste creates even more ecological damage, particularly when it is landfilled, as is common practice in many countries. In the anaerobic landfill environment, food waste decomposes to produce methane, a potent greenhouse gas. A study in the UK estimated that if disposed food were diverted from landfills, the net reduction in greenhouse gas impact would be equivalent to taking one out of every five vehicles off the road (WRAP 2011).

There is a pressing need for solutions that leverage innovation in clean technologies and environmental policies across the "food waste hierarchy" (Fig. 1). For example, many European countries have policies that ban

Callie W. Babbitt

cwbgis@rit.edu

1 Golisano Institute for Sustainability, 190 Lomb Memorial Drive, Rochester, NY 14623, USA or place a high cost on landfilling food and other organic wastes, a trend that is reflected in the progressive food waste policy landscape of South Korea and in the small but growing set of US cities and states enacting food waste diversion policies. While such efforts clearly provide a regulatory and/or economic framework from which food waste management can be dramatically improved, they also introduce new technological challenges.

For example, broader deployment of common food waste management technology, like anaerobic digestion, still faces economic and technological hurdles, including high capital costs, performance that fluctuates with variability in incoming food waste $\mathrm{pH}$, nutrient content, organic loading rate, and moisture content, among other parameters, and low-cost incumbent competitors (e.g., biogas produced in anaerobic digestion competes against traditional fossil natural gas, which is currently at sustained low prices). Many papers in Clean Technologies and Environmental Policy grapple with these challenges. In this Issue, Montenegro Camacho et al. (2017) demonstrate that reforming biogas to hydrogen as a fuel cell feedstock offers promising techno-economic outcomes, and more studies such as this are needed to propose and evaluate how to optimally use biogas and other food waste valorization products.

In addition to traditional treatment options like anaerobic digestion and composting, novel food waste conversion technologies are a nascent field of study. Valorization via liquefaction, hydrolysis, gasification, pyrolysis, or combinations of technologies into food waste biorefineries all offer technological promise, but still face scale-up, economic, or environmental hurdles. As these technologies are being advanced and evaluated, it is incumbent on researchers to evaluate both the technical and sustainability outcomes of proposed solutions. Further, greater 


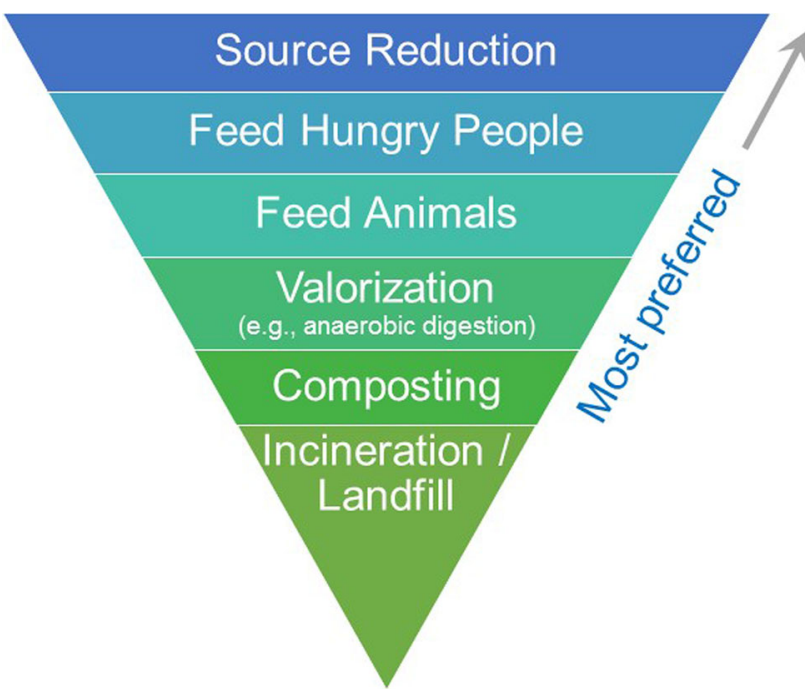

Fig. 1 Food waste recovery and management hierarchy. (Adapted from the US Environmental Protection Agency)

consideration must be given to how the methodological approaches and presentation of findings within a single study relate to this growing field of knowledge.

It is common practice to demonstrate performance of new technologies on food waste streams that are readily at hand or regionally specific, which may limit the generalizability of findings to other areas or waste compositions. Unfortunately, physical and chemical characterizations of these unique waste mixtures are often incomplete or inconsistent in published studies, further limiting the ability for literature review or meta-analysis to elucidate emergent relationships between food waste characteristics and system performance, cost, and environmental footprint. We invite papers for this journal that advance this body of knowledge, from fundamental technology development, to systems-level sustainability analysis, and even to the challenge of standardization and inter-study comparability and methodological harmonization.

\section{References}

Gustavsson J, Cederberg C, Sonesson U, Van Otterdijk R, Meybeck A (2011) Global food losses and food waste. Food and Agriculture Organization of the United Nations, Rome

Montenegro Camacho YS, Bensaid S, Piras G et al (2017) Technoeconomic analysis of green hydrogen production from biogas autothermal reforming. Clean Technol Environ Policy. doi:10. 1007/s10098-017-1341-1

Pimentel D, Williamson S, Alexander CE, Gonzalez-Pagan O, Kontak C, Mulkey SE (2008) Reducing energy inputs in the US food system. Hum Ecol 36(4):459-471

US EPA (2017) Food Recovery Hierarchy. www.epa.gov/sustainablemanagement-food/food-recovery-hierarchy. Accessed 1 May 2017

Canning P, Charles A, Huang S, Polenske KR, and Waters, A (2010) Energy use in the US food system. Economic Research Report No. 94. USDA

WRAP (2011). Estimates for household food and drink waste in the UK 2011. http://www.wrap.org.uk/content/estimates-householdfood-and-drink-waste-uk-2011. Accessed 1 May 2017 